\title{
Chapter 2 \\ Mergers and Alliances in France: Incentives, Success Factors and Obstacles
}

\author{
Andrée Sursock
}

\subsection{Introduction}

The number of mergers and alliances in higher education has grown recently in Europe, and France has not escaped this general trend. An unpublished survey of the 34 national associations of universities that are members of the European University Association (EUA) shows that, as of November 2012, 21 associations reported activities in this area. The survey revealed that motivations for such activities could be grouped into four categories (several of which may be relevant to a single country): economies of scale; enhanced regional or international impact; increased quality via the rationalisation of the education offer and the consolidation of a fragmented research sector; and creating new synergies in education and research by seizing on the opportunity of a demographic decline. Although these might be shared objectives, they should not conceal important contextual differences. Thus, this chapter presents the evolving French policy context that has led to recent mergers and alliances in universities. The stand-alone schools of engineering or of commerce are also engaged in a similar process but these types of institutions are not part of this historical account because their motives and trajectory for engaging in such activities are somewhat different from those of the universities.

The chapter is based on several empirical sources: the author's direct involvement in the evaluations of four French alliances (two regional alliances, an institutional merger and an international consortium involving French universities), in the international visiting board of a Parisian university, and in the 2012 review of French higher education and research that was initiated by the government following François Hollande's election in 2012. The chapter is also based on formal and informal discussions held with French university leaders over the course of nearly 20 years, as well as a number of printed sources.

\footnotetext{
A. Sursock $(\bowtie)$

European University Association, Brussels, Belgium

e-mail: andree.sursock@eua.be 
This chapter shows that alliances and mergers have been promoted by institutional leaders as a step toward rationalising French higher education and research, consolidating its various elements, and improving its impact internationally. It is the result of at least 50 years of policy development. However, if these steps were perceived as logical and important by decision makers and many university presidents, they were not perceived as such by some of the rank-and-file academics, particularly when these policies were viewed through the prism of partisan politics and ideology. The new government of François Hollande decided to examine the impact of past legislative reforms and consider new legislative changes. These are currently under discussion. To use Christine Musselin's apt words, this is indeed "the long march of the French universities" (Musselin 2001). The interested reader is warned that the legal saga is not finished; its next episodes will have to be found elsewhere than in this chapter.

\subsection{The Foundations of the French Higher Education System}

French higher education and research policies of the past decades have been aimed at addressing two perceived weaknesses of the system - hyper-centralisation and hyper-fragmentation. In the interest of brevity, it could be said that the seeds of these two weaknesses were sown in the eighteenth century.

\subsubsection{Fragmentation}

Around the French Revolution, the state created the first "grandes écoles" through the establishment of the Ecole normale supérieure and the Ecole polytechnique. These institutions followed in the footpath of older tertiary (non-university) institutions that were dedicated to the training of engineers, including of military personnel. Access to the "grandes écoles" has been through a concours (a highly selective competition), a feature that is explained as being fundamental to reinforcing democracy because it ensures that social mobility is based on merit rather than birth. In other words, the process of elite formation through a concours has been viewed as fair and democratic because - theoretically - everyone holds the same chances to success. Although Bourdieu and Passeron (1990) showed the extent to which the system reproduced elites, the ideological commitment to this approach has not wavered.

The fragmentation of institutions of higher learning produced a model that is unique in the world in that small, specialised, elite schools (the grandes écoles) are at the apex of a pyramid whose base is constituted by large, multidisciplinary universities that are required to accept any holder of a baccalauréat, without any 
selection or even academic orientation. This means, for instance, that the holders of professional and technological baccalauréats have access to the universities even though these baccalauréats were meant to lead into vocational higher education. This situation results in relatively high failure rate in the first year of university and a sense, on the part of the universities, that they are given worthy social mobility and democratic objectives but without the financial means to succeed. Indeed, the universities receive less funding per student than the grandes écoles.

The fragmentation of the higher education landscape was further aggravated by a policy of reinforcing research outside the universities. This was embodied by the most visible of all research organisations, the prestigious Centre national de la recherche scientifique (CNRS). (To note, there are several other such organisms but the acronym CNRS is used in this chapter as shorthand for all of them.).

\subsubsection{Centralisation}

The Emperor Napoléon I created the imperial university, managed centrally by the ministry. In the process of creating one university (with a multitude of branch faculties across France), the imperial power, in effect, destroyed the French universities qua institutions. There were institutions that continued to be called universities but these were empty shells and the government dealt with the branch faculties directly. This reality was reflected in the most common way that the general public spoke of universities, referring to them as " $f a c$ " for faculties. The institutions had no autonomy in relation to their "autorité de tutelle" - a very strong expression referring to their ministry and suggesting the extent to which the ministry ran the universities' affairs.

Managed centrally meant that - at least, in principle - all universities had the same mission, and the same profile as prescribed by law. In fact, the legal framework was so detailed that, over the years, the universities came to teach study programmes whose components were defined centrally. They had little leeway to innovate, particularly for the first years of the initial cycle. This has changed relatively recently but the temptation of central regulation is still very strong.

\subsection{From the 1960s to the 1990 s}

Between the mid-1960s and the mid-1990s, three important processes emerged within the higher education system, which were somewhat at odds with one another.

- Firstly, a rapprochement between the universities and the research organisations started with the creation of "associated laboratories" (university laboratories co-funded by the CNRS) and later, the unités mixtes de recherche (UMR), or joint research units: these brought researchers from the universities and the 
CNRS or equivalent organisations into the same laboratories. The universities, however, felt that the CNRS was strengthening its own research capacity by picking the best brains in the universities.

- Secondly, autonomous faculties were regrouped by the government into one or more universities in some cities. Thus, three universities replaced the Université de Grenoble; three, the Université de Strasbourg; four, the Université de Bordeaux; etc. To take the example of Nancy, newly formed Nancy 1 became specialised in sciences and medicine, Nancy 2, in social sciences and the humanities and the Institut national polytechnique de Lorraine regrouped several engineering schools. To a certain extent, the new universities represented an attempt to promote a level of interdisciplinarity but within a rather small range of disciplines. It was only in the smaller - to medium-size towns that truly interdisciplinary, comprehensive universities (with or without medicine) were found. In addition, a history of autonomous faculties cannot be erased easily and lingering, nostalgic feelings contributed to centrifugal tensions within the newly created universities (Finance 2012).

- Thirdly, France recognised that the legal framework should support the new universities by providing more autonomy and strengthening their leadership. Perhaps this was a rational political response to the massification of higher education and the realisation that the sector had become too big to be managed centrally. In an attempt to strengthen both the universities and their leadership, the institutions were asked to develop and negotiate a strategic project with the ministry that was enshrined in a multi-year contract. The contract strengthened the central leadership of universities and required the university presidents and the top leadership teams to shape and coordinate an institutional strategy. The universities were assigned an advisor (a former university president) who served as coach and mentor to the presidential team and advised during the process of developing and negotiating the contracts. The ministry, however, paid these advisors; as such, they had to balance the interests of the universities with that of their employer. Some ended up feeling that they represented the ministry in one of the most important negotiations between each university and the ministry (Jean-Pierre Finance, private communication).

These three policies were somewhat in contradiction and, as any other policy, had unintended consequences - at least three consequences in this case, as elaborated below.

\subsubsection{Universities Evolved Different Organisational Cultures}

Although the universities were generally restructured along disciplinary lines, in some cases, the restructuring also reflected political (left/right) fractures: some universities split along party lines and it was left up to individual professors to decide which university to join. This crystallised long-standing tensions that had survived over the years. 
Even if the restructuring along disciplinary lines was friendlier, it resulted over time in diverging organisational cultures amongst neighbours. As an example of this, the organisation of research is vastly different in the universities focused on the humanities and social sciences (where research is generally an individual pursuit) to the way it is organised in scientific universities (generally characterised by teamwork, and requiring more institutional investment: funding, equipment, health and safety measures, etc.). As a result, the scientific universities tend to be more hierarchical and disciplined. Student participative culture is also different and the terms of engagement are generally more political and turbulent in the former group of universities than in the latter. As will be noted, these contrasting cultural differences turned into challenges to be overcome when cooperation became a goal at the turn of the twenty-first century.

\subsubsection{National vs. International Prestige Strategies}

The policy of boosting the universities' research capacity through a rapprochement with the research organisations had a downside because two categories of laboratories were created in the process: the UMR that were mentioned above and the laboratoires d'accueil, which received funding from their university rather than from the CNRS and similar bodies.

The UMR were considered to be the top laboratories in France, and as a result, researchers identified more strongly with their laboratories (if it was a UMR) than with their universities. Researchers valued the UMR label, using it for their individual promotion at national level, but this strategy undermined their university's international visibility because the researchers signed off their publications using other affiliations (the laboratory, the funding research organisation, etc.) than the name of their university.

When the Shanghai Ranking appeared in 2005, it had the effect of a bombshell: only three French universities were in the Top 100 and the "grandes écoles" or the research organisations did not feature in the Top 100. In an effort to understand the roots of the problem, a scientific and medical university (Université Lyon 1) undertook an inventory of the ways in which its researchers listed their affiliations in academic publications and came up with the staggering number of over 50 different ways! The compounded individualistic strategies aimed at gaining national prestige, resulted in the loss of the researchers' university affiliation and a weakening of the aggregate international impact of French university research, which became hardly visible in the newly created international rankings.

\subsubsection{Institutional Strategic Capacity}

Furthermore, the multiplicity of research structures resulted in institutional inertia on the part of the universities, due to a lack of institutional self-confidence and 
pervasive individualism. In other words, the structures did not help individual academics and these academics, in turn, did not support the structures. In addition, the continued central steering from the ministry did not contribute to building institutional strength and effective leadership.

Over time, however, the institutional contract and other measures served to build up the strategic capacity of French universities. A new generation of presidents emerged who became attuned to stronger and more effective leadership. A number of these presidents was no longer willing to accept a situation characterised by under-funding, limited institutional autonomy and lack of student orientation and advisory support, which, in the 1980s and 1990s, led to overcrowding and a high failure rate in the first cycle. The university presidents complained that they were trapped between two types of more powerful organisations: the grandes écoles on the one hand, which were properly funded, had more autonomy and could select their students; and, research organisations, on the other, which had their own national research strategies into which the universities were expected to fit rather than they themselves shape. The universities felt, for good reason, that they were the handmaidens of the sector, financially strapped and politically squeezed between the national research organisations and the "grandes écoles". Both types of institutions were considered as the elite part of the sector and, as such, had the ear of the policy makers in Paris. It did not help matters that the top politicians and civil servants had been generally educated in the "grandes écoles" rather than in the universities and had little exposure to research-based teaching.

\subsection{The First Steps Toward Ever-Closer Alliances}

Around the year 2002, the universities in Grenoble became the trailblazer in France when they established "Grenoble Universités". This was an umbrella organisation to organise and promote cooperation across the universities in Grenoble. Grenoble Universités announced that it would drop the plural to indicate a much closer cooperation. A number of French universities followed this model. They set up their own umbrella organisations with some starting to discuss possible mergers in order to increase their critical mass and address their chronic under-funding.

An article - whimsically entitled Napoléon renversé (Napoleon upside down) by Aust and Crespy (2009) - describes how this consolidation movement started as a grass-roots initiative, i.e., at the initiative of some university presidents rather than coming from the ministry.

The ministry supported this movement. The regional and national governments took several initiatives to encourage such partnerships. In 2003, the ministry proposed a structure for such cooperation that found few takers. A year later, at the time of the implementation of the Bologna reforms, the then director general of higher education, Jean-Marc Monteil (2004), wrote to the universities emphasising that their future contracts should integrate a strong element of local partnerships (universities, schools, teachers' training colleges, university 
hospitals, etc.) and that it was "vital to ensure the coherence of the local educational offer in order to contribute to regional development, within an international perspective" (author's translation).

\subsection{Devolution to Regional Authorities and the Emergence of the "PRES"}

Shortly afterward, an initiative, accompanied by financial incentives, to boost regional partnerships was launched: this was the Pôles de recherche et d'enseignement supérieur (PRES), which joined a set of similar regional initiatives such as the Réseaux thématiques de recherche avancée (RTRA) and the Centres thé matiques de recherche et de soins (CTRS). These initiatives were part of a general effort to decentralise and devolve power to regional and local actors (Laperche and Uzunidis 2011) - a process that had started already in the 1980s with the "Université 2000" plan.

As in other parts of the world, Silicon Valley was the model that central and regional actors wanted to emulate. This was a far cry from the traditional French approach to industrial development that had been centrally driven, with the state defining the overall approach (say, the development of nuclear power) and deciding the local applications (in this case, the location of the nuclear plants). Such centralised planning was guided by the notion that, to the extent that it is possible, there would be a harmonious development across the country. The code words for this equalising treatment are l'aménagement $d u$ territoire (or regional development).

The new funding instruments were conceived in a selective and competitive way. Thus, the PRES funding was supposed to be concentrated on ten sites but, by 2012, there were 26 PRES.

According to Aust and Crespy (2009), the university presidents who were most successful at promoting a PRES had a similar professional profile: for the most part, they were scientists who led scientific universities and whose professional trajectory included an advisory or expert role to the ministry in Paris, their regional authorities and the European institutions. In the process of driving their change agenda, these promoters adopted a top-down approach and excluded from the initial discussions important sections of the university community and the decisionmaking bodies, including the staff and student unions and the faculty deans (Aust and Crespy 2009). This would come back to haunt them a few years later.

The main objectives of the PRES have been to increase critical mass and improve international visibility. Thus, typical activities include the coordination of doctoral education (via common doctoral schools), shared policies for the acquisition, use and maintenance of scientific equipment and facilities; common internationalisation strategy (promotion, exchanges, agreements, etc.); joint initiatives for knowledge transfer and joint signatures on scientific publications. 
The PRES were successful to the extent that they encouraged the university leadership to be more strategic and to work better with their regional authorities, the neighbouring grandes écoles and the local branches of the research organisations. These are notable achievements even if it has taken time for partners to learn to work together and if it was challenging to create cohesion when status, salaries and identities differed across a wide variety of partners. In addition, some PRES have gone as far as undergoing mergers (Aix-Marseilles, Lorraine).

It remains to be seen, however, if the PRES will bring added value or if they turn into a new layer of bureaucracy that would have no positive impact on academic strategies.

\subsection{Between Excellence and Regionalism}

In addition to the PRES and the other funding instruments, several reforms were introduced during the Chirac (1995-2007) and the Sarkozy (2007-2012) presidencies. These included a new law on public finance (LOLF); a "pacte de la recherche" that saw the creation of a research funding agency (Agence nationale de la recherche, ANR) and a new evaluation agency (Agence d'évaluation de la recherche et de l'enseignement supérieur, AERES); a restructuring of the national research organisations, such as the CNRS; and a new law on university autonomy (LRU).

\subsubsection{A French Excellence Initiative}

In addition to these measures, competitive funding was strengthened through the plan campus and a programme called "investissements d'avenir". The first was meant to fund ten campuses of excellence. The selection was based on four criteria: the academic project, the condition of the physical plan, the development of campus life and the anchoring in a region. The second programme included a variety of instruments such as: Equipex to fund intermediate size laboratory equipment, Labex to fund innovative scientific teams, and IDEX to support the emergence of a small and select number of alliances and mergers. These instruments were conceived as the French version of the German Excellence Initiative; in other words, this policy - particularly the IDEX - concentrated resources on a few "world-class" universities, perceived as the key drivers of economic growth in a knowledge-based economy.

It is important to note the quick succession and pileup of initiatives - some of which were pulling in different directions. Eric Froment, who played a role in the Lyon PRES and is a keen observer of French higher education and research development, noted (private communication) that the PRES emphasised partnerships and cooperation but that the LRU introduced an individual logic: indeed, 
the universities had to apply and be given approval in order to be allowed to implement the newly enlarged scope of autonomy. In a number of PRES, some universities felt they were ready for the LRU whilst others amongst their partner institutions in the PRES were not ready or were even politically against what they perceived as a neoliberal policy. These different approaches weakened these PRES, at least in the short term. When the IDEX were next introduced, they injected once more a culture of partnerships but with a new twist: a stress on excellence and a competitive and elitist bent, which was not as strong a feature in the initial culture of the PRES.

In addition, some of the funding instruments were in contradiction with the historic way that research had been funded. National funding policy had not always been linked to evaluations and wavered between excellence and egalitarianism (depending on the political orientation of the government). Research funds were sometimes allocated to universities that did not have the appropriate research capacity even if a nearby institution had more research capacity. In such cases, research would be carried out by a UMR that would include CNRS (or equivalent) researchers and university researchers, thus providing a weaker university team the opportunity to conduct higher quality research. This was done in an attempt to level off regional differences. The planning arm of the state tried (theoretically) to ensure that the aménagement du territoire was as fair as possible. Although this approach ended in the 1990s, regional devolution meant that the criteria for funding research continued to include some consideration of the need to build regional research capacity.

Given this history, the IDEX and associated competitive funding instruments created tensions at multiple levels:

- Tensions within the university community at large: a total of eight megaalliances of universities were funded through the IDEX. This extra funding was concentrated in Paris and four other regions, leading to resentment and questions of fairness and sustainability, such as: Will this policy result in turning big stretches of France into an "academic desert"? What would be the effect of such a policy in the long haul? Is it sustainable to concentrate resources to this extent? Are these mega-universities sustainable and will they succeed?

- Tensions between the IDEX-funded alliances and the neighbouring universities that were not part of the alliances, e.g., between the universities located in the centre of Paris and those in the immediate suburbs; in Alsace, between the Université de Strasbourg and the nearby Université de Mulhouse.

- Tensions across the different alliances within Paris, for instance, over which alliance would seize the coveted Sorbonne brand name (since all the Parisian universities are the daughters of the August alma mater).

- Tensions within each university that received IDEX or Labex funding: by pitting the staff unions against the university leadership, whom they criticised for the lack of collegial decision making in constituting the alliances, and in playing off one laboratory against another as a result of the competitive Labex funding model. 
Thus, these tensions and the pace of recent change have been reverberating across all levels, within each university and up to the level of the sector at large, including, therefore the French conference of university presidents (CPU), which has been struggling, at times, to find consensus amongst its members. Indeed, diverging views have found their ways into the printed press, with one group or another of university presidents signing a letter putting forward minority views on crucial issues for the sector. For instance, 11 presidents signed an open letter denouncing the LRU, the recent law on autonomy (AEF 2013). Alternatively, the statements emanating from the CPU have been sometimes qualified as de l'eau tiède (lukewarm water), an expression referring to their lack of punch as they strive to reach consensus. Needless to say, these challenges were understandable and many other associations of universities across the world have had to find a way to deal with increased competition within their midst.

\subsubsection{The Increased Role of Regional Governments}

The shift towards concentrating resources and supporting a few pockets of excellence should also be seen in the context of a shift of power from the central to the regional governments in France. The gradual devolution of power toward regional governments meant that these became increasingly sensitive to the need to have a regional knowledge strategy. Those regional governments with a good tax base and strong universities (that produced the regional political elite) were well placed to provide funding instruments to their knowledge institutions, thus also contributing to diversification and rivalry from a national perspective.

Increasingly, the regional governments learnt how to support their universities to the point that some wanted to go so far as defining the universities' strategy. This prompted the then minister for higher education and research (Laurent Wauquiez) and the then director for higher education (Patrick Hetzel) to warn the university presidents during their 2012 annual colloquium about the danger of "glisser d'une tutelle à l'autre", i.e. the risk of losing the hard-earned autonomy that had been bestowed by the central government in exchange for less autonomy vis-à-vis the regional governments.

The tension between the central and regional governments was exacerbated during the Sarkozy era because the vast majority of regional governments were in the hands of the Socialist Party. This also had consequences for higher education, particularly in the Paris region, where some projects became hostage to fortune. For example, the new Condorcet campus in Paris and nearby Aubervilliers, specialised in the social sciences, has been in the planning stage since 2007. It brings together four universities, several research organisations, several institutes, about $200,000 \mathrm{~m}^{2}$ of new buildings, the Paris City Hall, the regional authorities and the ministry. So far, no building has risen from the ground. Tensions between the socialist regional government and the Sarkozy government over how to co-finance the Condorcet development seemed to have slowed down the start of the project. The Sarkozy 
government favoured Public Private Partnerships (PPP) for the plan campus projects, including this one, whilst the regional government favoured a public offer and funding. The vice president of the regional authority, Isabelle This Saint-Jean, is quoted as saying:

The former government wanted to impose PPP and considered the regional authority as a cash cow; its communication about the project was inaccurate whilst nothing had ever been built. This arm wrestling has considerably slowed down the project (Stromboni 2013b).

The Condorcet campus is also emblematic of the confusion that is being created by multiple, interlocking initiatives: here is one new organisation - Condorcet that is composed of ten different institutions, some of which are involved in different Parisian PRES. Thus, Université Paris 1 is part of a PRES called HéSam; universities Paris 3 and 13 are part of the Paris Cité PRES; and Université Paris 8 is part of the Paris Lumière PRES. It is difficult to see how these overlapping affiliations will be managed and guided down a coherent path.

\subsubsection{The Recent Mergers}

It is a relief then to travel from Paris south to Marseille or northeast to Strasbourg and the Lorraine. There, universities have managed to merge and to consolidate. As was mentioned earlier, universities across France were restructured in the 1970s. The first to merge were the three universities in Strasbourg (2009) followed by the three universities in Aix-en-Provence and Marseille (2012) and the three universities in Nancy with the University of Metz in Lorraine (2012). Other mergers have been announced in Bordeaux, Montpellier, and Toulouse, to name a few; whether these will be successful and all-inclusive remains to be seen.

If the PRES include universities and non-universities (grandes écoles, etc.), the mergers are only taking place amongst universities. The Université de Lorraine includes the schools of engineering that were the constituent parts of the Institut national polytechnique although this institute has the same legal status as universities. This consolidation movement has been accelerated by the IDEX funding. Once the decision to fund eight big projects was taken, it accelerated mirroring strategies elsewhere even if questions were being asked about the "mastodontes" (mammoths) that such a dynamic was creating. Was big really that beautiful? Wasn't the California Institute of Technology tiny and successful? Is going big the only strategy open to an underfunded sector and its only chance to exist on the world stage? The answer is tentatively positive if, for instance, the Shanghai ranking is taken as a measure of success since its indicators are calculated in absolute rather than relative numbers. In this case, big is indeed better! (Rauhvargers 2011).

Regardless of these lingering questions, many had changed their minds and come to realise that French universities needed to be reformed in order to increase the span of their interdisciplinarity, rationalise the educational offer and built on 
specific research strengths. The mergers and alliances were a way of triggering such a strategic change process. It remains to be seen if this was the most effective and least painful way of achieving such objectives. At the same time, some universities are resisting the movement. Thus, in Bordeaux and Montpellier, the humanities universities have dissociated themselves from their local merger projects. In other parts of France, it is the engineering schools that were concerned in preserving their identity and independence. It will be interesting to see if these institutions will encounter difficulties in creating a niche for themselves in the future.

Other French universities decided to link closely some of their units (e.g., in Créteil and Marne-la-Vallée, and Dijon and Franche-Comté). These experiences offer the opportunity to practise a rapprochement on a small scale and prepare a more ambitious institution-wide merger, with its attendant administrative challenges. Most importantly, it often gives a role to the rank-and-file who also see immediate academic benefits ([...] or not) in increasing their critical mass.

Still other universities (such as those in Lille, Lyon, Rennes, etc.) decided to strengthen cooperation without going through the obstacle course that mergers represent. Each of their individual stories - and their twists and turns - shows the extent of the difficulties entailed. For instance, the three universities in Lille (Lille 1,2 and 3) were not always on the same page: at some point, Lille 2 decided against a closer alliance and stayed on the sidelines whilst Lille 1 and 3 made progress in discussing cooperation; recently Lille 2 changed its position and joined the closer alliance again but on condition that merging is no longer an option. Therefore, in an attempt to lower the tensions, the future shape of the Lille project is now shrouded in ambiguity and its contours are no longer defined.

A very candid interview with Fabienne Blaise, the new president of Université Lille 3, is very revealing in this respect (Stromboni 2013a, b). She identifies the following three sets of factors that have contributed to the meanderings and the delays:

- The focus of the early discussions in Lille was about the institutional aspects of the project; these were the most complex (Although she does not say this, presumably, it would have been more useful to discuss the academic benefits of the merger instead of the administrative ones; this would have served to stimulate and motivate the academic community).

- Although working groups had been organised, the lack of university-wide discussion was evident. This project was being discussed within the top leadership teams and involved presidents and vice-presidents. This led to conspiracy theories and resulted in the failure of two university presidents to get re-elected. The third president was re-elected but "understood that he needs to work in a different way", i.e., consult more effectively. (It is interesting to note that the third president led the scientific university and that he is the only one who survived his critics.).

- The social science and humanities university asked for reassurance that its needs would not be overshadowed by those of the science university. 


\subsubsection{The University Leadership vs. The Rank-and-File}

All these experiences helped to indicate to the university leadership that the time for single solutions to complex problems was over. A very strong consensus emerged amongst them around a key word: "souplesse" (flexibility). In other words, they insisted that the legal framework should remain sufficiently open to allow a range of institutional solutions.

The academic rank-and-file, however, was in a different place. Some of the staff unions have been resisting the double shift: the shifting power from the central state to the regional authorities and, more worryingly for them, to the presidential teams in the universities. Naturally, they could only view as a threat any strategy that made power more distributed and therefore more proximate. Their strengths derived from being able to organise themselves as a bloc against central national policies. Introducing greater differentiation, regional devolution and institutional autonomy could only dilute their collective punch.

In addition, excellence-driven policies have a cost, including human ones as noted by Patricia Pol:

Permanent stress, pressures and frustrations generated by competition are some of the factors contributing to unhappiness and imbalance. The time spent negotiating risky agreements, the cost of coordinating these new cooperative structures increase the workloads of academics at the risk of driving their attention away from their core mission of research and teaching (Pol 2012).

It is in this context that the Hollande government decided to conduct a thorough review of the most recent reforms with the stated aim of correcting the negative effects of past initiatives via a new law. At time of writing (Feltesse 2013), Vincent Feltesse, the parliament rapporteur for the new law, was conducting preliminary hearings in preparation for the parliamentary debate. His blog sought to reassure its readers by stating that the law will give flexibility to a range of groupings - mergers, alliances (communautés) and associations (rattachements). These groupings could straddle administrative boundaries and the ministry would be required to sign a contract with each grouping.

Rumour had it, however, that the contracts would be signed by the grouping of all institutions within each academy (with the exception of Paris). These academies are administrative units led by a recteur d'académie, who represents the state on all matters pertaining to education and higher education.

It is easy to see why the ministry would prefer to operate in this standardised bureaucratic way, given the increased complexity caused by the interlocking of structures, as shown for instance in the Condorcet example discussed earlier.

When the idea that the ministry would deal with only a single grouping was broached with Fabienne Blaise in Lille, she responded in a sharp tone that there were four groupings rather than one in the Lille "académie" and that the ministry would have to make do with the situation: "They can't tell us, just like this, with a snap of their fingers: 'we want to talk to one grouping'. This irritates me. It won't push us to cooperate and it won't reduce complexity. Most importantly, I would not want this to act as a break on the grouping dynamic." (Stromboni 2013a, b). 


\subsection{Concluding Remarks}

It is clear that the sector has undergone a number of major policy changes and challenges. Their accumulation has been difficult to manage and the situation is far from being stabilised. The gains that have been made over the years could be lost as the sector is still prone to wide policy swings with respect to the links between the universities, the research organisations, the grandes écoles and both the national and regional authorities.

Stronger institutional leadership is emerging but it remains to be seen if it will be able to motivate staff and students and provide incentives for change in an unfavourable economic context. In addition, leadership is a necessary but not sufficient condition. University leadership is exercised in an arena that includes multiple actors - staff and student and their unions, "grandes écoles", research organisations, national and regional authorities - and these will not be necessarily pushing in the same direction. The historical tendency toward centralisation and fragmentation might once again prevail unless good university leadership is combined with the capacity of the central state to change and adapt and if the regional authorities resist the siren call of increased power.

Acknowledgements I am grateful to Jean-Pierre Finance and Eric Froment for their careful reading of this paper and their invaluable comments.

Open Access This chapter is distributed under the terms of the Creative Commons Attribution Noncommercial License, which permits any noncommercial use, distribution, and reproduction in any medium, provided the original author(s) and source are credited.

\section{References}

AEF. (2013). Lettre ouverte a Madame la Ministre de l'Enseignement Supérieur et la Recherche et aux élus de la Nation: "Pour une loi de l'Enseignement Supérieur et la Recherche ambitieuse, concertée, a la hauteur des enjeux réels" [Online]. Available at: http://blog.educpros.fr/ pierredubois/files/2013/02/11-présidents-contre-la-loi-Fioraso-cliquer-ici1.pdf. Accessed 28 Feb 2013.

Aust, J., \& Crespy, C. (2009). Napoléon renversé? Institutionnalisation des Pôles de recherche et d'enseignement supérieur et réforme du systeme académique français. Presses de Sciences Po: Revue française de science politique, 59, 915-938. http://www.cairn.info/revue-francaise-descience-politique-2009-5-page-915.htm

Bourdieu, P., \& Passeron, J. C. (1990). La Reproduction: Éléments pour une théorie du systeme d'enseignement, Editions de Minuit. In Reproduction in education, society and culture (Theory, culture and society series). London: Sage.

Feltesse, V. (2013). Mon journal de rapporteur. Rapporteur. République française: Assemblée Nationale Commission des affaires culturelles et de l'éducation. http:// monjournalderapporteur.tumblr.com

Finance, J. P. (2012). La gouvernance et l'organisation. In F. Frédéric (Ed.), Les universities en France: fonctionnement et enjeux (pp. 40-56). Paris: Presses Universitaires de France. 
Laperche, B., \& Uzunidis, D. (2011). The impacts of reforms on research and innovation in France: Direction, planning and co-ordination. Higher Education Management and Policy, 23(2), 9-26. http://www.oecd.org/edu/imhe/HEMP\%20v23-2\%202011.pdf

Monteil, J. M. (2004). 0403249 Direction de la recherche et de l'enseignement supérieur. Circulaire. République Française.

Musselin, C. (2001). La longue marche des universités françaises. Paris: Presses Universitaires de France. The long March of French Universities, New York, Routledge.

Pol, P. (2012). La passion de l'excellence dans l'enseignement supérieur en Allemagne. Mai: Reperes.

Rauhvargers, A. (2011). Global university rankings and their impact [Online]. http://www.eua.be/ pubs/Global_University_Rankings_and_Their_Impact.pdf

Stromboni, C. (2013a). Interview of Fabienne Blaise (Lille 3): "Nous ne sommes pas encore tous d'accord sur la pertinence d'une université unique" [Online]. Available at: http://www. letudiant.fr/educpros/entretiens/fabienne-blaise-lille-3-nous-ne-sommes-peut-etre-pas-encoretous-d-accord-sur-la-pertinence-d-une-universite-unique.html. Accessed 27 Mar 2013.

Stromboni, C. (2013b). Opération campus: Condorcet avance. a son rythme [Online]. Available at: http://www.letudiant.fr/educpros/actualite/operation-campus-condorcet-avance-a-son-rythme. html. Accessed 19 Feb 2013. 